\title{
When Old Meets New: Wholesale and Agency Models in the Market for Printed and Electronic Books
}

\author{
Antino Kim \\ Kelley School of Business \\ Indiana University \\ antino@indiana.edu
}

\begin{abstract}
In this work, I seek explanations to some of the curious phenomena reported in the book market by focusing on its two important characteristics: (i) the substitutability between the printed-and the e-book versions, and (ii) the mixture of the "old" wholesaling arrangement for printedbook versions and the "new" agency model for e-book versions. In this exploration, using a game theoretic model, I find that an increase in the agency fee that the retailer collects in the e-book market can depress the vitality of the market, which not only ends up hurting the publisher, but also the retailer. This raises a caution that retailers should be moderate in their efforts to get a bigger cut in the agency arrangement. I also find that some of the perplexing phenomena observed in the real world may be due to an excessively large agency fee in the e-book market, and that reducing this fee can lead to a win-win outcome for both the publisher and the retailer.

Keywords: Retailing, book, e-book, wholesale, agency, revenue-sharing, substitutes, game theory.
\end{abstract}

\section{Introduction}

Tug of war best describes the tension between Amazon - an online retail giant with a huge presence in the book market - and some of the major publishers - often referred to as the "Big Five" - in deciding their retail arrangements for both printedand e-books. Traditionally, printed-books have been sold through a wholesaling arrangement where a publisher first sells to a retailer at a wholesale price, and the retailer then resells to consumers at a retail price. Amazon wanted to extend this model to the ebook market to control the retail price of e-books as well. The publishers, however, had something else in mind; they wanted to adopt the agency model where they get to decide on the final retail price and pay a certain fraction of their revenue to the retailer as an agency fee. In 2016, it seemed the publishers had gotten their way; the publishers made Amazon agree

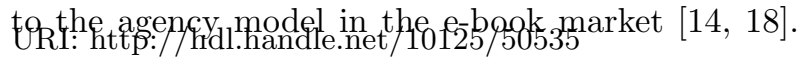
ISBN: 978-0-9981331-1-9

(CC BY-NC-ND 4.0)
However, since this adoption of agency arrangement, something puzzling has happened: the e-book market has shrunken against the anticipation that it would flourish and, in contrast, the printed-book market has grown. Moreover, the e-book prices have gone up whereas the printed-book prices have gone down, and the publishers' profits have decreased whereas Amazon's profit has increased [2, 12, 13]. Such outcomes are quite ironic considering how aggressively the publishers have pushed to gain control over their e-book price: Why could the publishers not benefit from having more control over their e-book price? Did the publishers overlook something while forcing Amazon to agree to the agency arrangement? Mike Shatzkin - the founder and CEO of The Idea Logical, a New York publishing consultancy - shares something that raises a suspicion that the publishers might not have fully understood the repercussions of moving to the agency model in the e-book market. He writes, "...four of the five big publishers think agency has been a big mistake. As one observer sees it, it has bled $25 \%$ out of digital sales that have been replaced by physical, resulting in an increased share for Amazon of the print portion of publishers' businesses" [13]. In stark contrast, according to Shatzkin, "Amazon is now happy with the fact that they have no control over the final retail price of e-books" [12].

What can be gathered from the reports stated above is the interconnected nature between the printed- and the e-book markets. Specifically, in this work, I focus on two defining market characteristics: (i) printed books and e-books are partially substitutable, and (ii) e-books are now sold through the agency model whereas printed books are still sold through the wholesaling setup. I refer to this arrangement as the agency-mix, which is in contrast to the previous pure-wholesaling setup where both products are sold through the wholesaling arrangement. So, in the overall book market, both the old scheme of

\section{H I C S S}


wholesale and the new agency model clash, creating complications that some describe as a "threedimensional chess" [12]. In this work, I attempt to delineate the dynamics between the publisher and the retailer in the book market, and provide explanations to the perplexing real world phenomena observed.

To that effort, I construct a parsimonious model where the publisher sells its printed books through the wholesaling arrangement with the retailer, and sells the electronic version through the agency model. This setup captures the essence of the market that, for printed books, the retailer sets the final retail price while, for e-books, the publisher sets the retail price. From my analyses, I discover several interesting findings that are of managerial importance. First of all, unlike what the conventional wisdom tells us, the retailer's profit in the e-book market is not monotonically increasing in the agency fee it collects in the e-book market. This is because of the strategic response from the publisher; as the retailer collects more agency fee in the e-book market, the publisher finds that market less attractive, and thus increases the e-book price with the intention of nudging consumers to move to the printed-book market. Such a reaction from the publisher may depress the e-book market to a degree where the retailer actually loses from charging a higher percentage as the agency fee. Moreover, this loss in the e-book market can end up hurting the retailer's overall bottom line. This finding raises a caution that retailers should perhaps be moderate in their efforts to get a larger cut of the pie in the e-book market. I also discover that an excessively high agency fee alone can account for the perplexing phenomena observed in the market today. Faced with two options - either to go back to purewholesaling or to reduce the agency fee while keeping the agency-mix model-I find that the latter can lead to a win-win outcome for both the publisher and the retailer.

\section{Literature Review}

This research relates to the growing list of literature that considers both the agency and wholesaling setups. For example, [9] explores the setting with upstream competition between the manufacturers and identifies the cases where the retailer benefits from external third party information concerning the quality and the fit of the product. There, the authors consider the wholesale case and the agency case in separate settings.

[1] is one work that considers the coexistence of both the wholesaling and the agency arrangement.
The authors examine to see when online retailers should use agency selling over wholesaling based on the severity of the competition among them and the level of spillover effect to the traditional channel. The authors find that agency selling leads to a more efficient outcome and that retailers would prefer agency selling when electronic sales substitute the demand in the traditional channel. They do not, however, consider a case where one retailer engages in both agency selling and wholesaling.

The setup used in [19] is similar to the one used in this paper in the sense that it also captures a case where the retailer sells traditional goods through wholesaling and digital goods through an agency setup. While the model details differ, the authors also find that the agency model might be preferred to the traditional wholesaling setup by both the publisher and the retailer. However, they find that the retailer can only do better with a higher agency fee, which is in stark contrast with one of the main messages of this work. The key reason for this discrepancy is in the timing; in [19], the authors assume that the e-book's retail price is determined before that of the printed version. However, since the publisher has full control over the e-book's retail price-and the retailer over the printed-book's retail price - it is more reasonable to assume that the retail prices are best response functions of each other. Hence, in this work, I assume that the retail prices of both versions are simultaneously determined.

[6] is another important part of the foundation this work is built upon. There, the authors focus on the complementary relationship between e-books and ereaders, and they identify this complementary relationship as the main reason for the low e-book prices in the wholesale model. Compared to the wholesaling case, in the agency setting, the price for e-book readers is lower, the price for e-books is higher, and the publisher becomes worse off. Unlike the analyses in this paper, they conduct the study with exogenous price for the printed books. At the core of their results is the argument that the issue of double marginalization can be addressed by selling the e-reader, as it essentially serve as a two-part tariff mechanism. However, contents are becoming increasingly platform independent, thanks to platform virtualization. People can now read e-books on their own devices through the use of apps. Based on this reality, I do not consider platform aspects in my analyses. A natural consequence of this exclusion is that I can immediately preclude any complementary effect from the possible reasons for the findings.

The wholesale model has long been in used and widely adopted in the retailing industry. Once a manufacturer sells its products to a retailer, it page longer 
needs to keep track of them. From the retailer's point of view, once it purchases the product from the manufacturer, it has the freedom to set whatever retail price to go with its overall market strategy. This convenience and flexibility are among the main reasons for the popularity of the wholesaling arrangement. However, that is not to say that such an arrangement is without any problems. One of the most well-known issues of wholesaling is the issue of double-marginalization, which has long been recognized by economists [17]. When a monopolistic manufacturer sells through a monopolistic retailer, the vertical externality manifests itself as a higher retail price, a lower demand, and a reduced channel profit. The resulting literature is so vast that it is impossible to do justice in the short literature review section of this work, and the interested reader is referred to the excellent surveys in [3] and [7]. Among the many ideas that have been proposed to address the issue of double-marginalization-such as resale price maintenance, franchise fee, etc. - is the idea of revenue-sharing agreements, which is at the core of agency models $[3,11]$. However, it has also been demonstrated that revenue sharing may not be a panacea for double marginalization. For instance, if costly advertising becomes critical to boosting sales, it can be shown that royalty payments based on a revenue-sharing formula would not coordinate the channel [4, 5]. Along the same line, this work also shows that revenue-sharing arrangement does not automatically translate to lower margins and a lower retail price for e-books.

\section{Model and Analyses}

Following the realities of the book market today, I first consider the case where e-books are sold through agency model and printed-books are sold through wholesaling. For ease of reference, I refer to this mixture of wholesaling and agency model as agency-mix. Later, in $\S 5$, I consider a case where both products are sold through wholesaling, and I refer to that retail setting as pure-wholesaling.

In the agency-mix model, the timeline of events is as follows: First, the publisher sets the wholesale price $\left(w_{b}\right)$ of the printed-book version. Then, the retailer sets the retail price $\left(p_{b}\right)$ of the printed books, and the publisher sets the price $\left(p_{e}\right)$ of the e-books. This sequence captures the fact that (i) the wholesale price is typically determined before the retail prices are, and (ii) that the retail prices are relatively more fluid compared to the wholesale price. Once the retail-prices are set, the demand for each version is formed based on the prices and the substitutability between the two versions. Following backward induction, I describe the demand functions, and subsequently, the profit maximization problems of the publisher and the retailer.

\subsection{Demand Functions}

I assume that the two versions (i.e., printed- and ebook versions) are symmetric and differentiated, and the consumers make a purchase decision based on (i) the retail prices they see and (ii) the substitutability between the two. I adopt a commonly used linear demand function that satisfies both of these assumptions $[1,8,15,16,10]$. The demands for printed- and e-books - $q_{b}$ and $q_{e}$, respectively - are:

$$
\begin{aligned}
q_{b} & =\frac{1}{1+\sigma}-\frac{1}{1-\sigma^{2}} p_{b}+\frac{\sigma}{1-\sigma^{2}} p_{e}, \text { and } \\
q_{e} & =\frac{1}{1+\sigma}-\frac{1}{1-\sigma^{2}} p_{e}+\frac{\sigma}{1-\sigma^{2}} p_{b},
\end{aligned}
$$

where $p_{b}$ and $p_{e}$ are retail prices of printed- and ebook versions, respectively, and $0<\sigma<1$ represents the level of substitutability between the two versions.

As it is obvious from the lack of any explicit incentive compatibility constraints, I do not restrict the consumers from purchasing both versions. For instance, if the two products are substantially different - and not highly substitutable - a consumer who purchases the printed version may also purchase the electronic version. Hence, the total demand is $q_{b}+q_{e}=\frac{2-p_{b}-p_{e}}{1+\sigma}$, which clearly shrinks as the two versions become more substitutable. This is intuitive since, when the two versions are highly substitutable, consumers who purchase one version would be less likely to consider also purchasing the other. ${ }^{1}$

\subsection{Publisher's and Retailer's Decisions}

Anticipating the demands, the publisher and the retailer set the retail prices. The interesting aspect in the agency-mix setting is that the retail price of each version is set by a different party. For e-books, the firms are in an agency arrangement, where the publisher directly controls the retail price $\left(p_{e}\right)$ and, as an agency fee, pays the retailer $\alpha \in(0,1)$ fraction of the retail price for each copy sold. For the printed-book version, the firms engage in a wholesale agreement, where the publisher sets the wholesale price $\left(w_{b}\right)$ and the retailer adds its margin to the wholesale price, effectively setting the retail price, $p_{b}$. This combination of agency and wholesale arrangements between the publisher and the retailer is summarize in Figure 1 .

\footnotetext{
${ }^{1}$ As a side note, I have also considered different models in which the total demand does not change with $\sigma$. For example, I considered a case where $q_{b}=1-p_{b}+\sigma\left(p_{e}-p_{b}\right)$ and $q_{e}=$ $1-p_{e}+\sigma\left(p_{b}-p_{e}\right)$, leading to a total market size of $2-p_{b}-p_{e}$. However, the results do not change qualitatively. Page 5176
} 


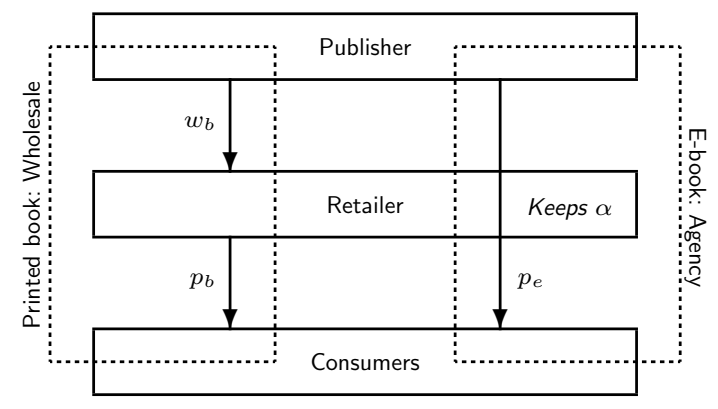

Figure 1. Publisher and Retailer Relationship

From the setting, the profits for the publisher and the retailer- $\Pi_{H}$ and $\Pi_{A},{ }^{2}$ respectively — can be written as:

$$
\begin{aligned}
& \Pi_{H}=q_{b} w_{b}+(1-\alpha) q_{e} p_{e}, \text { and } \\
& \Pi_{A}=q_{b}\left(p_{b}-w_{b}\right)+\alpha q_{e} p_{e} .
\end{aligned}
$$

Both firms set the retail prices - the publisher, $p_{e}$, and the retailer, $p_{b}$ - to maximize their profits. Simultaneously solving for the first-order conditions $\left(\frac{d \Pi_{H}}{d p_{e}}=\frac{1-2 p_{e}(1-\alpha)-\alpha+\left(w_{b}-\left(1-p_{b}\right)(1-\alpha)\right) \sigma}{1-\sigma^{2}}=0\right.$ and $\frac{d \Pi_{A}}{d p_{b}}=$ $\left.\frac{1-2 p_{b}+w_{b}-\left(1-p_{e}(1+\alpha)\right) \sigma}{1-\sigma^{2}}=0\right)$ results in the following optimal retail prices:

$$
\begin{aligned}
p_{e}^{*} & =\frac{2-\left(1+\sigma-3 w_{b}\right) \sigma-\alpha\left(2-\sigma+\left(w_{b}-\sigma\right) \sigma\right)}{(1-\alpha)\left(4-(1+\alpha) \sigma^{2}\right)}, \text { and } \\
p_{b}^{*} & =\frac{1}{(1-\alpha)\left(4-(1+\alpha) \sigma^{2}\right)}(1-\alpha)(1-\sigma)(2+(1+\alpha) \sigma) \\
& +w_{b}\left(2(1-\alpha)+(1+\alpha) \sigma^{2}\right) .
\end{aligned}
$$

It is easy to verify that the second-order conditions $\left(\frac{d^{2} \Pi_{H}}{d p_{e}{ }^{2}}=-\frac{2(1-\alpha)}{1-\sigma^{2}}<0\right.$ and $\left.\frac{d^{2} \Pi_{A}}{d p_{b}{ }^{2}}=-\frac{2}{1-\sigma^{2}}<0\right)$ are also satisfied.

Substituting the retail prices in (3) and (4) with (5) and (6), I get the profits as functions of $w_{b}$. To find the optimal $w_{b}$ the publisher chooses in the first stage, I once again examine the first-order condition: $\frac{d \Pi_{H}}{d w_{b}}=\frac{(1-\alpha)\left(8(1-\alpha \sigma)+(1+\alpha)^{2} \sigma^{3}\right)-2 w_{b}\left(8(1-\alpha)+(1+\alpha)^{2} \sigma^{2}\right)}{(1-\alpha)\left(4-(1+\alpha) \sigma^{2}\right)^{2}}=0$. This leads to the following expression for the wholesale price of the printed-book version:

$$
w_{b}^{*}=\frac{(1-\alpha)\left(8(1-\alpha \sigma)+(1+\alpha)^{2} \sigma^{3}\right)}{16(1-\alpha)+2(1+\alpha)^{2} \sigma^{2}} .
$$

Here as well, the second-order condition $\left(\frac{d^{2} \Pi_{H}}{d w_{b}{ }^{2}}=\right.$ $\left.-\frac{16(1-\alpha)+2(1+\alpha)^{2} \sigma^{2}}{(1-\alpha)\left(4-(1+\alpha) \sigma^{2}\right)^{2}}<0\right)$ is satisfied.

\footnotetext{
${ }^{2}$ As a mnemonic, I suggest that the readers associate the subscript $H$ with HarperCollins Publishers - one of the world's largest publishing companies - and $A$ with Amazon.
}

\section{Equilibrium and Results}

I now describe the equilibrium outcomes. First, solving $q_{e}=0$ for $\alpha$ with the optimal prices from (5), (6), and (7), I obtain $\bar{\alpha}$ above which the market for e-book disappears:

Lemma 1. For $\alpha \geq \bar{\alpha}=\frac{1}{\sigma^{2}(1+\sigma)}(4+\sigma(3-\sigma(1+\sigma))-$ $\sqrt{16+\sigma(24-\sigma(7+8 \sigma(3+\sigma)))})$, the market for e-book disappears.

The above lemma shows that when $\alpha$ is excessively large - that is, when the retailer sets out to collect too much from e-book sales - the e-book market ultimately collapses. Intuitively as well, when $\alpha$ grows excessively high, leaving the publisher close to nothing for e-book sales, the e-book market will become less and less attractive to the publisher, who responds strategically to the change in $\alpha$. Later, in the comparative statics, I describe in detail how the players respond to the change in dynamics as represented by $\alpha$ and how the equilibrium changes accordingly.

As the primary interest of this work is in the equilibrium regions where both the printed books and e-books are sold, hereafter, unless stated otherwise, all results are for the range where $\alpha<\bar{\alpha}$. Within that range, the optimal profits for the publisher and the retailer are denoted as $\Pi_{H}^{*}$ and $\Pi_{A}^{*}$, respectively. ${ }^{3}$ For completeness, note that the profits for $\alpha \geq \bar{\alpha}$ can be obtained by simply replacing $\alpha$ with $\bar{\alpha}$ in the profit expressions; since the e-book market disappears for $\alpha \geq \bar{\alpha}$, the change in $\alpha$ does not affect the profits in that range.

Let us now examine the profit expressions closely. Intuitively, the publisher ought to always desire a lower $\alpha$ while the retailer should prefer the exact opposite [19]. The question then arises, does that simple intuition extend to my setup?

First, from the above profit expressions, I can infer a divergence between the incentives of the publisher and the retailer. Intuitively, the publisher always prefers to pay a lower agency fee, that is, the publisher's profit $\left(\Pi_{H}^{*}\right)$ strictly decreases in $\alpha$. This is because as the publisher forks over a larger portion of the profit from the e-book sales to the retailer,

\footnotetext{
${ }^{3}$ For interested readers, the detailed profit expressions are as follows:

$$
\begin{aligned}
\Pi_{H}^{*} & =\frac{(1-\alpha)\left(4(3+\sigma)-(1+\sigma)\left(8 \alpha-\sigma^{2}(1+\alpha)^{2}\right)\right)}{4(1+\sigma)\left(8(1-\alpha)+\sigma^{2}(1+\alpha)^{2}\right)}, \text { and } \\
\Pi_{A}^{*} & =\frac{1}{4(1+\sigma)\left(8(1-\alpha)+\sigma^{2}(1+\alpha)^{2}\right)^{2}} \\
& \left(16(1-\alpha)^{2}((1+4 \alpha)-\sigma(1-4 \alpha))\right. \\
& +4 \sigma^{2}(1+\alpha)\left(4-\alpha\left(1+\alpha+4 \alpha^{2}\right)\right) \\
& -4 \sigma^{3}(1+\alpha)(4-\alpha(9+\alpha(1-4 \alpha))) \\
& \left.+\sigma^{4}(1+\alpha)^{3}(4(1-\sigma)+\alpha(1+\alpha)(1+\sigma))\right) .
\end{aligned}
$$
}

Page 5177 
its overall profit decreases. On the other hand, the retailer generally prefers a higher agency fee but not always since $\Pi_{A}^{*}$ may actually decrease in $\alpha$; for the retailer, it turns out, the situation is a little more complex than what the common intuition might suggest. I formally summarize this profit observation as the first proposition:

Proposition 1 (Total Profit). The publisher's profit $\left(\Pi_{H}^{*}\right)$ strictly decreases in $\alpha$. However, the retailer's profit $\left(\Pi_{A}^{*}\right)$ may be non-monotonic in $\alpha$. Specifically, when $\sigma \geq \hat{\sigma}$, where $\hat{\sigma} \approx 0.697, \Pi_{A}^{*}$ strictly increases in $\alpha$. However, when $\sigma<\hat{\sigma}, \Pi_{A}^{*}$ increases in $\alpha$ until $\hat{\alpha}$ and decreases, where $\hat{\alpha}$ is the unique root for $512(1+\sigma)(1-\alpha)^{3}+64 \sigma^{2}\left(5+3 \alpha\left(\alpha^{3}-2(1+\alpha)\right)\right)+$ $64 \sigma^{3}\left(1+3 \alpha\left(\alpha^{3}+2(1-\alpha)\right)\right)+4(1+\alpha)^{2} \sigma^{4}(29-17 \sigma-$ $\alpha(\alpha(5+7 \sigma+6 \alpha(1+\sigma))-6(1+\sigma)))+(1+\alpha)^{4} \sigma^{6}(5 \sigma+$ $\alpha(2+\alpha)(1+\sigma)-3)=0$ within $0<\alpha<1$.

Thus, beyond a certain threshold, increasing $\alpha$ can be a losing proposition, both for the publisher and the retailer. This finding is in clear contradiction not only to the common intuition but also to the suggestions from prior literature. For instance, [19] demonstrates that the retailer with a higher negotiating power would always opt for a higher $\alpha$. In contrast, the above proposition implies that even when the retailer's bargaining power is great enough to command a large $\alpha$, it may be in the retailer's best interest not to; it might be a better strategic move to yield more to the publisher.

I now examine the e-book market and the printedbook market separately by taking a closer look at the partial profits from each market. ${ }^{4}$ Hereafter, all expressions for printed- and e-book markets are marked by subscripts $b$ and $e$, respectively. ${ }^{5}$ Once again, the partial profits for the region where $\alpha \geq \bar{\alpha}$ can be obtained by simply replacing $\alpha$ with $\bar{\alpha}$ in the

${ }^{4}$ Note that these are not optimal values since the players optimize their total profits not their partial ones.

${ }^{5}$ For interested readers, the detailed partial profit expressions are as follows:

$$
\begin{aligned}
\Pi_{H b}= & \frac{(1-\alpha)\left(8(1-\alpha \sigma)+(1+\alpha)^{2} \sigma^{3}\right)\left(2+\sigma^{2}-\alpha\left(2-\sigma^{2}\right)\right)}{2(1+\sigma)\left(8(1-\alpha)+(1+\alpha)^{2} \sigma^{2}\right)^{2}}, \\
\Pi_{H e}= & \frac{1}{4(1+\sigma)\left(8(1-\alpha)+(1+\alpha)^{2} \sigma^{2}\right)^{2}}(1-\alpha)(8(1-\alpha)+ \\
& \left.2(1+\alpha) \sigma-\left(1-\alpha^{2}\right) \sigma^{2}\right)\left(8(1-\alpha)+(2-6 \alpha) \sigma+(1+\alpha)^{2} \sigma^{2}\right. \\
& \left.+(1+\alpha)^{2} \sigma^{3}\right), \\
\Pi_{A b} & =\frac{1}{2(1+\sigma)\left(8(1-\alpha)+(1+\alpha)^{2} \sigma^{2}\right)^{2}} \\
& \left(4(1-\alpha)(1-\sigma(1-2 \alpha))+2 \sigma^{2}(1+\alpha)^{2}-\sigma^{3}(2-\alpha)(1+\alpha)^{2}\right) \\
& \left(2+\sigma^{2}-\alpha\left(2-\sigma^{2}\right)\right), \text { and } \\
\Pi_{A e} & =\frac{1}{4(1+\sigma)\left(8(1-\alpha)+(1+\alpha)^{2} \sigma^{2}\right)^{2}} \alpha(8(1-\alpha)+2 \sigma(1+\alpha) \\
& \left.-\sigma^{2}\left(1-\alpha^{2}\right)\right)\left(8(1-\alpha)+2 \sigma(1-3 \alpha)+\sigma^{2}(1+\alpha)^{2}(1+\sigma)\right) .
\end{aligned}
$$

partial profit expressions. Obviously, when $\alpha \geq \bar{\alpha}$, the e-book market collapses, so $\Pi_{H e}=0$ and $\Pi_{A e}=0$.

First off, I see that the change in $\alpha$ not only affects the equilibrium outcomes in the e-book market but also those in the printed-book market. Though $\alpha$ is the agency-fee percentage within the ebook market - and hence an important indicator of the dynamics between the players in that marketcuriously, it appears to have a spill-over effect in the printed-book market as well. Specifically, the profit for the publisher from the printed-book market decreases with $\alpha$ whereas that for the retailer strictly increases.

As is the case with the total profit, the publisher's partial profit from the e-book market falls with $\alpha$ as the publisher yields a larger fraction of the revenue from the e-book market to the retailer. So, it seems that, as $\alpha$ increases, the publisher bleeds in both markets whereas the retailer always benefits in the printed-book market and may also benefit in the e-book market-provided that $\alpha$ is not excessively high. Once again, beyond a threshold, the retailer's profit from the e-book market diminishes. This thusly shows that the conventional wisdom that a higher agency fee would always benefit the retailer does not necessarily hold even within just the e-book market. I summarize these findings formally in the next proposition:

Proposition 2 (Partial Profit). In the printedbook market, the profit of the publisher strictly decreases in $\alpha$ whereas that of the retailer strictly increases. In the e-book market, the profit of the publisher strictly decreases in $\alpha$ whereas that of the retailer may be non-monotonic in $\alpha$. Specifically, when $\sigma \geq \check{\sigma}$, where $\check{\sigma} \approx 0.917, \Pi_{A e}$ strictly increases in $\alpha$. However, when $\sigma<\check{\sigma}, \Pi_{A e}$ increases in $\alpha$ until $\check{\alpha}$ and decreases, where $\check{\alpha}$ is the unique root for $32(3+\alpha(\alpha(\alpha(6 \alpha-1)-9)-7)) \sigma^{2}+$ $32\left(3+6 \alpha-6 \alpha^{3}+5 \alpha^{4}\right) \sigma^{3}+256(1-\alpha)^{3}(2+\sigma)+(1+$ $\alpha)^{2} \sigma^{4}(12-4 \alpha(\alpha(7+6 \alpha)-14)+8 \alpha \sigma(\alpha(1-3 \alpha)-2)+$ $\left.\sigma^{2}(1+\alpha)^{4}-\sigma^{3}(1+\alpha)^{2}(1-\alpha(2+\alpha))\right)=0$ within $0<\alpha<1$.

Proposition 2, together with Proposition 1, conveys a clear message for the retailer. Though it may be tempting for the retailer to always push for a higher $\alpha$, it might not be in the retailer's best interest to do so. Above a certain threshold, the profit from the ebook market may actually decrease in $\alpha$, ultimately reducing the total profit for the retailer. A retailer blindly following the common intuition and the suggestions from prior literature may always fight for a higher $\alpha$, which may be suboptimal for the retailer. 
The proposition also carries a message for the publisher, though the message is a little more subtle than the one for the retailer. As one may expect, the publisher loses as $\alpha$ increases. The more nuanced point is that the reduction in the publisher's profit is due to the fact that the publisher loses in both markets. As $\alpha$ increases, its primary effect on $\Pi_{H e}$ is easy to predict. However, the secondary effect on $\Pi_{H b}$ may not be as so; a bigger $\alpha$ reduces not only $\Pi_{H e}$ but also $\Pi_{H b}$. With this new finding, now, the publisher has an added incentive to push for a lower $\alpha$. Only focusing on the impact of agency fee in the e-book market may lead to neglecting other possible negatives on the publisher's overall profit, leading to an underestimation of the impact of rising $\alpha$.

All profit-related results presented so far are direct consequences of the publisher's and the retailer's pricing decisions. To better understand the driving forces behind these findings, let us now take a closer look at the strategies of the players represented by their optimal prices:

$$
\begin{aligned}
& p_{b}^{*}=1-\frac{\sigma}{2}-\frac{2((1-\alpha)(1-\sigma))}{8(1-\alpha)+\sigma^{2}(1+\alpha)^{2}}, \text { and } \\
& p_{e}^{*}=\frac{8(1-\alpha)+2 \sigma(1+\alpha)-\sigma^{2}\left(1-\alpha^{2}\right)}{16(1-\alpha)+2 \sigma^{2}(1+\alpha)^{2}} .
\end{aligned}
$$

With these price expressions - which capture the strategies of the publisher and the retailer-the strategic interaction between the two players starts to unfold. First, when $\alpha$ increases - which generally represents a higher bargaining power of the retailer, or, conversely, a weaker position of the publisher - the price of e-book rises, that is, $\frac{d p_{e}^{*}}{d \alpha}=$ $\frac{(1-\sigma) \sigma\left(16-(1+\alpha)^{2} \sigma^{2}\right)}{\left(8(1-\alpha)+(1+\alpha)^{2} \sigma^{2}\right)^{2}}>0$. This is in contradiction with the notion that $p_{e}^{*}$, which is set by the publisher, represents the power of the publisher; it may be tempting to think that any given price represents the pricing power of the party that sets the price. However, directly contradicting that view, when the retailer is able to push for a higher cut in the e-book market, I see here that the publisher sets a higher $p_{e}^{*}$. This finding demonstrates that, though the "Big Five" attempted to gain autonomy from Amazon's grip in the e-book market by being able to set the prices themselves, their pricing decisions may be closely tied to their relative bargaining power and tied in a way that may not be immediately intuitive.

As shown in Proposition 2, the effect of $\alpha$ is not confined to the profits in the e-book market and has a spill-over effect on the profits in the printedbook market as well. Similarly, here, I observe that an increase in $\alpha$ raises not only the e-book price but also the printed-book price. That is, $\frac{d p_{b}^{*}}{d \alpha}=$ $\frac{2(3-\alpha)(1+\alpha)(1-\sigma) \sigma^{2}}{\left(8(1-\alpha)+(1+\alpha)^{2} \sigma^{2}\right)^{2}}>0$. To understand the logic behind the mechanism observed here, it is crucial to keep in mind that $p_{b}^{*}$ is set by the retailer while $p_{e}^{*}$ is set by the publisher. When the publisher needs to fork over a bigger fraction of the earning from each e-book sold, it finds the e-book market less desirable. Because of the substitutability between the two products, the publisher can raise the e-book price in order to nudge the consumers to migrate from the less desirable e-book market to the printed-book market. However, when the publisher increases $p_{e}^{*}$, the retailer finds itself in a position where it can also raise $p_{b}^{*}$ since the price of the competing product has increased. As a result, with increasing $\alpha$, I find that both the e-book and the printed-book prices rise.

I now analyze how the demand responds to the players' pricing strategies:

$$
\begin{aligned}
& q_{b}=\frac{2+\sigma^{2}-\alpha\left(2-\sigma^{2}\right)}{(1+\sigma)\left(8(1-\alpha)+\sigma^{2}(1+\alpha)^{2}\right)}, \text { and } \\
& q_{e}=\frac{8(1-\alpha)+2(1-3 \alpha) \sigma+\sigma^{2}(1+\alpha)^{2}(1+\sigma)}{2(1+\sigma)\left(8(1-\alpha)+\sigma^{2}(1+\alpha)^{2}\right)} .
\end{aligned}
$$

The above demand expressions reveal something interesting. Based on the basic intuition, since the retail prices increase as $\alpha$ increases, all else equal, the demands ought to decrease with $\alpha$. Additionally, it appears that the simple intuition holds as far as the e-book market is concerned; the demand for e-books decreases as $\alpha$ increases $\left(\frac{d q_{e}}{d \alpha}=\right.$ $\left.-\frac{16 \sigma-\sigma^{3}(7-\alpha)(1+\alpha)}{(1+\sigma)\left(8(1-\alpha)+\sigma^{2}(1+\alpha)^{2}\right)^{2}}<0\right)$. However, as soon as I turn to the printed-book market, this simple intuition does not apply. Though $p_{b}^{*}$ also increases as $\alpha$ increases, $q_{b}$ actually increases in $\alpha\left(\frac{d q_{b}}{d \alpha}=\right.$ $\left.\frac{2(5-\alpha(2-\alpha)) \sigma^{2}-\sigma^{4}(1+\alpha)^{2}}{(1+\sigma)\left(8(1-\alpha)+\sigma^{2}(1+\alpha)^{2}\right)^{2}}>0\right)$, implying that the demand for the printed-books increases as the price increases. Upon a closer observation, I find that, as $\alpha$ increases, the publisher raises $p_{e}^{*}$ a lot more aggressively compared to how the retailer raises $p_{b}^{*}$, that is, $\frac{d p_{e}^{*}}{d \alpha}>$ $\frac{d p_{b}^{*}}{d \alpha}$. Because of this difference in the rate in which $p_{b}^{*}$ and $p_{e}^{*}$ increase with $\alpha$, more consumers find the printed version to be relatively more desirable than the electronic version. As a result, the number of consumers choosing printed-books over e-books is greater than the number of consumers who forgo purchasing because of the high price. I summarize these observations below:

Proposition 3 (Price and Demand). As $\alpha$ increases, both $p_{e}^{*}$ and $p_{b}^{*}$ increase, but $p_{e}^{*}$ increases at a steeper rate compared to $p_{b}^{*}$. That is, $\frac{d p_{e}^{*}}{d \alpha}>\frac{d p_{b}^{*}}{d \alpha}>$ 0 . Because of this difference in the rates, while both prices increase with $\alpha$, only $q_{e}$ decreases whereas $q_{b}$ increases. That is, $\frac{d q_{e}}{d \alpha}<0$ and $\frac{d q_{b}}{d \alpha}>0$.

Page 5179 
With Proposition 3, now, the complete picture starts to unravel. As the publisher needs to fork over a bigger fraction of the profit from the e-book sales, the e-book market becomes less attractive to the publisher. Accordingly, the publisher raises the e-book price to push the consumers to the printed version instead. However, the increase in the e-book price allows the retailer to raise the printed-book price as well; the retailer just does so not as aggressively as the publisher raises the e-book price, which results in an increase in the printed-book demand and a decrease in the e-book demand. When $\alpha$ increases too much, the publisher, for all practical purposes, abandons the e-book market and raises $p_{e}$ rapidly. When that happens, the gain in the printedbook market may not enough to compensate for the loss in the e-book market for the retailer, and the total profit for the retailer would decrease. At an extreme value of $\alpha$-beyond $\bar{\alpha}$ - the e-book market essentially collapses, leading to a market where only printed books are traded.

There is now one remaining venue for investigation; why would the retailer increase $p_{b}^{*}$ less aggressively compared to how the publisher increases $p_{e}^{*}$ ? It is understandable that the publisher would desire this to happen so that it can effectively move consumers from purchasing e-books to printed-books. However, it is not clear what incentive the retailer has to hold back from increasing the printed-book price more aggressively. Let us now visit this last missing piece of the puzzle. Since the marginal cost is negligible, the wholesale price $w_{b}$ is the publisher's margin on the printed books, and $m_{b}=p_{b}-w_{b}$ is the retailer's margin for each copy sold. Additionally, for e-books, I can calculate how much margin each player gains per copy sold. For the publisher, the margin on each e-book is $w_{e}=(1-\alpha) p_{e}$, and for the retailer, $m_{e}=\alpha p_{e}$.

Proposition 4 (Margins). For both printedand e-books, the publisher's margins decrease with $\alpha$ while the retailer's margins increase. That is, $\frac{d w_{b}^{*}}{d \alpha}<$ $0, \frac{d m_{b}^{*}}{d \alpha}>0, \frac{d w_{e}^{*}}{d \alpha}<0$, and $\frac{d m_{e}^{*}}{d \alpha}>0$.

What Proposition 4 shows is that, for the retailer, $\alpha$ can be a device to nudge the publisher to lower the wholesale price of the printed books. This intricate relationship of how $\alpha$ - a parameter directly relevant to the e-book market - can serve as a strategic apparatus for the retailer in forcing the publisher to lower the wholesale price in the printed-book market has not been identified in prior literature.

I now illustrate the whole mechanism behind the results: Suppose that $\alpha$ has increased by $\Delta$. Then, the publisher would find the formerly optimal prices to be no longer optimal now that $\alpha$ has changed.
Accordingly, the publisher explores to see if it could do anything to improve its status by changing $p_{e}$ and $w_{b}$, its strategic levers. Since the e-book market is now less attractive, the publisher has an incentive to migrate consumers away from the e-book market and towards the printed-book market. With that in mind, the publisher increases $p_{e}$, expecting a compensation from the printed-book market to make up for the loss in the e-book market. However, in the printed-book market, it is not the publisher that sets the retail price, $p_{b}$; it is the retailer. And, this retailer has two reasons to increase $p_{b}$ : First, because of the increased $\alpha$, the e-book market is now more attractive to the retailer, and second, as the publisher increases $p_{e}$ the price of the competing good - the retailer can also afford to increase $p_{b}$ without significantly hurting the demand for the printed-book version. Anticipating this incentive of the retailer, the publisher sets $w_{b}$ in a way that it becomes suboptimal for the retailer to increase $p_{b}$ to a point where it would cancel out all the gains that the publisher expects from raising $p_{e}$. By decreasing $w_{b}$, the publisher is able to achieve exactly that; the publisher hands out an extra premium to the retailer, and this extra premium in the printed-book market takes away some of the relative appeal of the e-book market. As a result, the retailer does not raise $p_{b}$ as high as it would have had otherwise.

\section{Comparison with "Pure-Wholesaling"}

As discussed in $\S 1$, the publishers had to pressure Amazon into signing the agency agreement. The rational was simple; the emerging e-book market seemed promising, and the publishers wanted to be able to directly control the retail price instead of being under the control of Amazon's pricing decisions. Despite this simple sentiment, according to the reports, the outcomes seem to have gone in the opposite direction of what the publishers had hoped. The demand for e-books fell sharply, and the publishers' revenues have noticeably dropped. On the contrary, the demand for printed-books rose substantially, and Amazon-who initially resisted the agency-mix arrangement - actually gained from the transition. In this section, I seek explanations behind this puzzling outcome.

To understand what happened in the transition from the pure-wholesaling model to the agency-mix arrangement, a benchmark model that represents the pure-wholesaling model is needed. To make a fair comparison, I use the same demand specification as written in (1) and (2). The difference is in pthe profit 
expressions due to the different retailing arrangement; the profit expressions change from (3) and (4) to the following:

$$
\begin{aligned}
& \Pi_{H \omega}=q_{b \omega} w_{b \omega}+q_{e \omega} w_{e \omega}, \text { and } \\
& \Pi_{A \omega}=q_{b \omega}\left(p_{b \omega}-w_{b \omega}\right)+q_{e \omega}\left(p_{e \omega}-w_{e \omega}\right),
\end{aligned}
$$

where $\omega$ is added as a suffix to represent the pure-wholesaling arrangement. Similar to what was assumed earlier in $\S 3$, the wholesale prices are determined first by the publisher, and then the retail prices are set by the retailer. By backward induction, I solve for the retailer's pricing problem first and the publisher's pricing problem second. Solving for the first-order conditions $\left(\frac{d \Pi_{r \omega}}{d p_{b \omega}}=0\right.$ and $\left.\frac{d \Pi_{r \omega}}{d p_{e \omega}}=0\right)$ simultaneously, I obtain $p_{b \omega}{ }^{*}=\frac{1+w_{b \omega}}{2}$ and $p_{e \omega}^{*}=\frac{1+w_{e \omega}}{2}$. I also check the Hessian matrix to verify that the second-order conditions are satisfied, confirming that these prices are indeed the optimal prices for the retailer.

Anticipating such a response from the retailer, the publisher decides on the wholesale prices. After substituting the retail prices in the publisher's profit expression for the optimal prices obtained above, once again, I leverage the first-order conditions $\left(\frac{d \Pi_{H \omega}}{d w_{b \omega}}=0\right.$ and $\left.\frac{d \Pi_{H \omega}}{d w_{e} \omega}=0\right)$ and Hessian matrix to obtain the optimal wholesale prices for the publisher. As before, the equilibrium outcomes for the printedand e-books are marked by subscripts $b$ and $e$, respectively, with $\omega$ added as a suffix to represent the purewholesaling arrangement:

$$
\begin{aligned}
& w_{b \omega}{ }^{*}=w_{e \omega}{ }^{*}=\frac{1}{2}, p_{b \omega}{ }^{*}=p_{e \omega}^{*}=\frac{3}{4}, q_{b \omega}=q_{e \omega}=\frac{1}{4(1+\sigma)}, \\
& \Pi_{H b \omega}{ }^{*}=\Pi_{H e \omega}{ }^{*}=\frac{1}{8(1+\sigma)}, \Pi_{A b \omega}{ }^{*}=\Pi_{A e \omega}{ }^{*}=\frac{1}{16(1+\sigma)} .
\end{aligned}
$$

As can be seen, in equilibrium, the prices - wholesale and retail - of each market are independent of their counterparts in the other market. In other words, the level of substitutability $\sigma$ plays little role in the optimal prices, and the prices become what one can expect from any ordinary wholesaling model. ${ }^{6}$ That is because, in this pure-wholesaling model, though the two products are substitutable, there is no competition between the publisher and the retailer since the retailer sets both prices.

Moving forward, I aim to find an explanation for the current state of affairs in the book industry. According to the reports, after moving from purewholesaling to agency-mix, (i) publishers' profit has decreased whereas Amazon's profit has increased, (ii)

${ }^{6}$ From a simple model with linear demand, the wholesale price is $\frac{1}{2}$ and the retail price, $\frac{3}{4}$ [cf. 20, p. 175]. the e-book price has gone up whereas the printedbook price has gone down, and (iii) the demand for e-books has decreased whereas that for the printedbook has increased. In light of this reality, naturally, my curiosity is whether such a situation can be found in the comparison. Reassuringly, such an outcome is indeed possible when $\alpha$ is excessively high. For instance, when $\sigma=0.25$ and $\alpha=0.9$, it is clear that $\Pi_{H}^{*}(\approx 0.084)<\Pi_{H \omega}^{*}(=0.2), \Pi_{A}{ }^{*}(\approx$ $0.174)>\Pi_{A \omega}^{*}(=0.1), p_{e}{ }^{*}(\approx 0.847)>p_{e \omega}^{*}(=0.75)$, $p_{b}{ }^{*}(\approx 0.729)<p_{b \omega}{ }^{*}(=0.75), q_{e}(\approx 0.091)<q_{e \omega}(=$ $0.2)$, and $q_{b}(\approx 0.249)>q_{b \omega}(=0.2)$ :

REMARK 1 (Reality Check). There is a region where $\Pi_{H}^{*}<\Pi_{H \omega}^{*}, \Pi_{A}{ }^{*}>\Pi_{A \omega}^{*}, p_{e}{ }^{*}>p_{e \omega}^{*}, p_{b}{ }^{*}<p_{b \omega}{ }^{*}$, $q_{e}<q_{e \omega}$, and $q_{b}>q_{b \omega}$, faithfully reflecting the realities of today.

What may be surprising is that $p_{e}{ }^{*}$ can be higher than $p_{e \omega}^{*}$; it is commonly accepted that revenuesharing, in a parsimonious setting, eliminates the issue of double marginalization. By parsimonious, I mean no other retail channel via which a close substitute is sold. I bring in exactly those aspects and demonstrate that, when the agency fee is high, the retail price can increase even beyond the one plagued by double marginalization. Once again, this is because, as the agency fee increases, the e-book market becomes less attractive to the publisher, and the desire for the publisher to nudge consumers to the printed-book version increases.

Interestingly, the case highlighted in the above remark cannot occur for $\alpha$ values below $\alpha_{A}^{*}$, where $\alpha_{A}^{*}$ is:

$$
\alpha_{A}^{*}= \begin{cases}\hat{\alpha}, & \text { if } \sigma<\hat{\sigma}, \\ 1, & \text { otherwise }\end{cases}
$$

Basically, $\alpha_{A}^{*}$ is the threshold for $\alpha$ below which the retailer's profit monotonically increases with $\alpha$ in the agency-mix setting. This discovery hints at the possibility that, perhaps, the agency fee that Amazon is charging the "Big Five" publishers is suboptimal for both parties. This once again illustrates the importance of Proposition 1 as Amazon may actually be leaving money on the table. However, even if the retailer was aware of the results in Proposition 1 - and made sure it did not push $\alpha$ beyond $\alpha_{A}^{*}$ even when its negotiating power afforded it to - the publisher may still be worse off in the agency-mix setup. In a situation described in Remark 1, the publisher and the retailer have two options: Either (i) go back to the pure-wholesaling model, or (ii) reduce the agency fee. Is there a range for $\alpha$ where both parties can be better off in the agency-mix setting compared to the pure-wholesaling? I present my findipgs below: 
Proposition 5 (Profit Comparison). For $\alpha<$ $\alpha_{H \omega}$, the publisher would prefer the agency-mix but would prefer the pure-wholesaling for $\alpha$ beyond $\alpha_{H \omega}$, where $\alpha_{H \omega}$ is the unique real root for $\Pi_{H}^{*}=\Pi_{H \omega}^{*}$ for $0<\alpha<1$. For $\alpha_{A \omega}<\alpha<\alpha_{A}^{*}$, the retailer would prefer the agency-mix but would prefer the pure-wholesaling for $\alpha$ below $\alpha_{A \omega}$, where $\alpha_{A \omega}$ is the unique real root for $\Pi_{A}^{*}=\Pi_{A \omega}^{*}$ for $0<\alpha<\alpha_{A}^{*}$. Comparing the thresholds, I find that $\alpha_{A \omega}<\alpha_{H \omega}<\alpha_{A}^{*}$.

From Proposition 5, I can infer several important messages. Since $\alpha_{H \omega}<\alpha_{A}^{*}$, if the retailer had a substantial bargaining power to set $\alpha$ above $\alpha_{H \omega}$, the publisher would always be worse off in the agencymix model compared to the pure-wholesaling model. At the other end, when $\alpha$ is too low-below $\alpha_{A \omega}$ while the publisher would come out ahead with the agency-mix model, the retailer would not. This is probably what the "Big Five" publishers were hoping for and what Amazon was afraid of when they were considering transitioning from the pure-wholesaling setup to the agency-mix model. That explains why the publishers were so eager to move to the new retailing arrangement whereas Amazon was obviously reluctant.

As already seen from Proposition 1, generally, the retailer fares better with higher $\alpha$ whereas the situation is the opposite for the publisher. Hence, it should come as little surprise that the two players generally disagree in terms of the ideal value for $\alpha$. What Proposition 5 reveals is an extension of Proposition 1; not only do the players disagree in their desired levels of $\alpha$, they also disagree in when they prefer the agency-mix arrangement over the pure-wholesaling model.

Though this finding may initially appear bleak, not all hope is lost. Interestingly, I find that there is a region where agency-mix can be a "win-win" proposition for both the publisher and the retailer compared to the pure-wholesaling setup. For $\alpha_{A \omega}<$ $\alpha<\alpha_{H \omega}$, the agency-mix would be a better proposition for both the publisher and the retailer compared to the pure-wholesaling. This finding has an obvious implication. Though the retailer and the publisher would strive to pull $\alpha$ in their own desirable direction, it is clear that agency-mix is the arrangement they can both agree on, and an $\alpha$ value between $\alpha_{A \omega}$ and $\alpha_{H \omega}$ - not too high and not too low-is the range in which the agreement can happen. If any higher than $\alpha_{H \omega}$, the publisher will want to defect to the purewholesaling instead, and if lower than $\alpha_{A \omega}$, this time, the retailer would push back against the agency-mix arrangement.

Given the current situation, the publishers might have the urge to revert back to pure-wholesaling. In fact, there are some statements about the publishers' remorse from moving to the agency-mix model [13]. However, according to the findings of this work, that would be a rash knee-jerk reaction as the publishers can gain from the current agency-mix setting. My result shows that there is no region where purewholesaling is a win-win proposition for both parties; only agency-mix can provide that. Though there is a clear divergence in the incentives between the publisher and the retailer in setting the value of $\alpha$, my result can bring both parties to the negotiating table and ultimately encourage them to reach a win-win outcome.

\section{Discussion and Conclusion}

With the advent of e-books, also came the opportunity to experiment with a more innovative retailing arrangement as opposed to simply adopting the traditional wholesale model used to sell printed-books. As e-books are ordered and delivered digitally, the agency setup appears to be a suitable choice for the product; a publisher can directly monitor - using the retailer's platform - how many copies of e-books are being sold and how much of the total revenue it gets. The agency model has another appeal to publishers: Unlike the wholesaling setup, the publishers can directly control the final retail price of the e-books in the agency model. As the expectation for the ebook market ballooned, and as the publishers grew disgruntled with Amazon's pricing of e-books, the "Big-Five" publishers fought for the agency model for e-books, and the sentiment was that they had won the battle. It appears, however, that they may have lost the war; see the following report that describes the current state of affair:

"Revenue is down in e-books because Amazon, using their mercantile might, has been aggressively selling printed-backs and hardbacks after publishers took away their power to control e-book pricing. Now e-book prices are way up and print prices are way down, a situation that eats into the publishers physical distribution models and guts their e-book sales. Book pundits all over the web are blaming Amazon for its habit of aggressively pricing hardbacks and printed-backs after losing control of e-book pricing" [2].

Both perplexed and intrigued by such an outcome, in this work, I take a closer look at the relationship between a publisher and a retailer to untangle the mysteries behind what is observed in the printed- and e-book markets. First, I examine how the change in the agency fee in the e-book market influences the pricing strategies and the profits of the plavers 1 In 
this effort, I discover that, despite the common belief, the retailer does not always make a higher profit as it attempts to extract more from each e-book sold. It turns out that, as the agency fee increases, the publisher loses in both the printed- and e-book markets, and the retailer gains in both markets up to a certain level, beyond which the retailer may lose in the e-book market. This loss in the e-book market can more than offset the gain in the printedbook market, leading to the non-monotonicity in the retailer's total profit. I also find that, as the agency fee increases, the e-book demand decreases while the printed-book demand rises, even though the prices for both increase. Moreover, increasing the agency fee in the e-book market also puts the retailer in an advantageous position in the printedbook market, where the retailer can nudge the publisher to offer a lower wholesale price on the printed books. To the best of my knowledge, this work is the first to identify how the changes in the agency fee has a crossover influence on the publisher's margin in the printed-book market. Finally, I discover that Amazon may be collecting a sub-optimally high agency fee in the e-book market, leading to the odd outcomes highlighted in the quote above. Overall, I find that somewhat puzzling outcomes can occur because of how the two key factors - substitutability between the two products and the mixture of two retail arrangements - considered in this model manifest themselves in the equilibrium.

Despite the current high e-book prices and low demand, some remain optimistic, saying that "when e-book pricing returns to sanity, expect to see a lot more revenue from digital channels" [2]. However, according to the findings of this work, the high ebook prices may be a direct byproduct of the market structure, and the "sanity" may not be restored automatically without the efforts from both the publisher and the retailer. Still, that is not to say that all hope is lost with the agency-mix model. The good news is that there is a win-win region where both the publisher and the retailer are better off with the agencymix setting. In fact, the pure-wholesaling arrangement can never be a win-win proposition. Thus, my results would assist the publisher and the retailer to see eye to eye in their negotiation endeavor and to converge on a retailing configuration.

\section{References}

[1] V. Abhishek, K. Jerath, and Z. Zhang, "Agency selling or reselling? channel structures in electronic retailing," Management Science, vol. 62, no. 8, pp. 2259-2280, August 2016.
[2] J. Biggs, "Print and ebook revenue down as Amazon slashes prices," http://www.techcrunch.com/, September 2016.

[3] G. Cachon, "Supply chain coordination with contracts," Handbooks in operations research and management science, vol. 11, pp. 227-339, 2003.

[4] G. Cachon and M. Lariviere, "Supply chain coordination with revenue-sharing contracts: strengths and limitations," Management Science, vol. 51, no. 1, pp. 30-44, 2005.

[5] R. Gil and F. Warzynski, "Vertical integration, exclusivity, and game sales performance in the US video game industry," Journal of Law, Economics, and Organization, vol. 31, no. 1, pp. 143-168, August 2015.

[6] L. Hao and M. Fan, "An analysis of pricing models in the electronic book market," MIS Quarterly, vol. 38, no. 4, pp. 1017-1032, December 2014.

[7] M. Höhn, "Literature review on supply chain contracts," in Relational Supply Contracts. Springer, 2010, pp. 19-34.

[8] K. Jerath and Z. Zhang, "Store within a store," Journal of Marketing Research, vol. 47, no. 4, pp. 748-763, August 2010.

[9] Y. Kwark, J. Chen, and S. Raghunathan, "Platform or wholesale? a strategic tool for online retailers to benefit from third-party information," MIS Quarterly, 2016, forthcoming.

[10] J. Raju, R. Sethuraman, and S. Dhar, "The introduction and performance of store brands," Management Science, vol. 41, no. 6, pp. 957-978, June 1995.

[11] P. Rey and J. Tirole, "The logic of vertical restraints," The American Economic Review, vol. 76, no. 5, pp. 921-939, December 1986.

[12] M. Shatzkin, "ebook pricing resembles three dimensional chess," http://www.idealog.com/, September 2016.

[13] —, "A first at this blog: walking back the assumptions that were the basis of the last post," http://www.idealog.com/, February 2016.

[14] —, "If Amazon pricing of ebooks is the problem, is agency actually the right solution?" http://www.idealog.com/, February 2016.

[15] M. Shubik and R. Levitan, Market Structure and Behavior. Harvard University Press, Cambridge, MA, October 1980.

[16] N. Singh and X. Vives, "Price and quantity competition in a differentiated duopoly," The RAND Journal of Economics, vol. 15, no. 4, pp. 546-554, Winter 1984.

Page 5183 
[17] J. Spengler, "Vertical integration and antitrust policy," Journal of Political Economy, vol. 58, no. 4, pp. 347-352, 1950.

[18] R. Tagholm, "The aftermath of the agency model," February 2013. [Online]. Available: http://publishingperspectives.com/2013/02/ the-aftermath-of-agency/

[19] Y. Tan and J. Carrillo, "Strategic analysis of the agency model for digital goods," Production and Operations Management, vol. 26, no. 4, pp. 724-741, April 2017.

[20] J. Tirole, The Theory of Industrial Organization. The MIT Press, 1992. 